\title{
SOB O SIGNO DE AQUÁRIO: O PATRIMÔNIO MARAJOARA EM TEMPOS DE BELLE ÉPOQUE
}

\author{
Josiane Martins Melo ${ }^{1}$, Agenor Sarraf Pacheco ${ }^{2}$
}

RESUMO: Este artigo tem como objetivo analisar representações de patrimônios culturais da Amazônia Marajoara no período do boom da economia da borracha (1870 a 1912), especialmente, no que tange às edificações e mudanças nos espaços urbanos de municípios do Marajó dos Campos e do Marajó das Florestas. A questão problematizadora central procurou entender que patrimônios públicos foram produzidos no famoso período gomífero da Amazônia em cidades marajoaras. Para alcançar o entendimento dessa questão, a pesquisa procurou dialogar com dois grupos de materiais: a) estudiosos da temática da econômica da borracha, do patrimônio, da memória e da identidade; b) narrativas de cronistas, viajantes e jornalistas que registraram informações sobre o cotidiano urbano marajoara, com destaque para edificações, usos, sociabilidades e tensões, nas últimas décadas do século XIX e duas primeiras do século XX.

PALAVRAS-CHAVE: Patrimônio. Belle Époque. Amazônia Marajoara.

\section{Primeiras Palavras}

Este estudo tem como objetivo principal investigar representações que envolvem noções de patrimônio na Amazônia Marajoara no período de 1870-1920, o qual cobre o chamado tempo da Belle Époque na Amazônia. Concomitante a isso, pretende verificar produções e recepções de sentidos atribuídos ao patrimônio na região marajoara, no que tange às edificações e mudanças nos espaços urbanos de municípios do Marajó dos Campos e do Marajó das Florestas.

Dada a importância desse período bellepoqueano para a Amazônia, as questões que nortearam a investigação foram: a) Quais percepções sobre patrimônio emergem de documentos escritos acerca de municípios marajoaras? b) Que patrimônios públicos foram produzidos no famoso período gomífero em cidades marajoaras? e c) Quais alterações sofreram espaços urbanos

\footnotetext{
${ }^{1}$ Bacharelado em Museologia, Universidade Federal do Pará.

${ }^{2}$ Doutor em História Social, Professor da Universidade Federal do Pará.
} 
marajoaras em função das altas cifras de toneladas de goma elástica que saíram da região, especialmente do Marajó das Florestas? Com o intuito de mapear tais questões, este trabalho mostra como podemos operar diante das relações de poder, negociações e resistências dentro das questões patrimoniais.

Para responder as questões trabalhou-se na perspectiva metodológica da cartografia, conforme vem sendo apreendida por Pacheco (2013, p. 04) que a entende como um campo "não-linear, processual, dinâmico, rizomático, múltiplo". Para se estudar realidades histórico-sociais e socioculturais na esteira de uma "cartografia de memórias", é necessário apreender "a construção de conhecimentos sem dualidades, valorizando suas intersecções e interculturalidades."

Com base na perspectiva interdisciplinar que estabelece diálogo entre museologia, história e antropologia, a investigação centrou esforços no mapeamento, leitura e interpretação de escritores clássicos que descreveram episódios da história da Amazônia, desde o período colonial, narrativas de viajantes e, especialmente, o Jornal do Pará de 1870 a 1878 para captar a dinâmica geo-histórica do arquipélago de Marajó e construções urbanas em tempos de Belle Époque. A base teórico-historiográfica assenta-se em autores que discutem em suas pesquisas categorias como patrimônio, memória, identidade e representação, com destaque para escritos de Maria Cecília de Londres Fonseca, Michael Pollak, Françoise Choay e Roger Chartier.

No levantamento sobre o estado da arte em torno da Belle Époque, visitaram-se obras de alguns autores que discutem a economia da borracha na Amazônia. Assim, em A borracha na Amaz̧ônia: expansão e decadência (1850-1920), Barbara Weinstein (1996) revelou dados importantes da produção da borracha nos principais municípios no Pará, dentre eles, Afuá, Breves, Gurupá e Melgaço, todos localizados em parte do território marajoara que Pacheco (2006) denomina de Marajó das Florestas. Nas estatísticas organizadas pela pesquisadora, verifica-se uma grande produção da borracha nestes municípios, como Breves, que se destaca como o maior produtor entre 1900 a 1906 com os valores de 1.203 .398 a 1.547 .374 quilos. Por isso, pergunta-se: onde a riqueza gerada por essa extração e exportação foi aplicada? Ela ajudou a construir novas 
arquiteturas urbanas? Junto à procura desse entendimento, busca-se saber o que ganha caráter de patrimônio na lógica da gestão pública local e dos moradores.

O período da chamada Belle Époque na Amazônia é visto pela ótica de uma memória construída pelo fator de modernização e ideário de progresso pelo qual passaram algumas cidades da região Amazônica, como Belém e Manaus. Chama-se atenção para a escrita, os grandes feitos e ao grande processo de urbanização devido o período da Belle Époque evidenciar riqueza e prosperidade econômica, social, funcional, política e cultural. Essa perspectiva histórica de progresso, riqueza e modernização da Amazônia (em Belém) é analisada na obra Belém: riquezas produzindo a Belle Époque, de Maria de Nazaré Sarges. Também se pode ver em Memórias do "Velho Intendente” Antônio Lemos (1969-1973), como Maria de Nazaré Sarges irá reconstituir o processo de construção da imagem de Antônio Lemos na cidade de Belém, sem perder de vista o "outro lado" da Belle Époque, o lado dos sujeitos silenciados. Mas, o período da chamada Belle Époque na Amazônia não aconteceu apenas em Belém ou Manaus, reverberou-se, de maneiras diferentes, em outras partes da Amazônia e do mundo. Em $A$ ilusão do Fausto de Edinea Mascarenhas Dias, uma abordagem crítica sobre a representação do fausto da Belle Époque, a autora trabalhou as contradições no cotidiano da cidade e procurou desmitificar a imagem construída em torno de uma Manaus da prosperidade eterna da bela época. Em Migrantes Cearenses no Pará: faces da sobrevivência (1889-1916), Franciane Gama Lacerda mostra experiências sociais dos cearenses em terras paraenses. Visibilizando outras vozes, a autora mostra como se processa a migração de homens e mulheres cearenses para o Pará no período da borracha e as dificuldades sofridas pelos migrantes.

A partir de artigos publicados na Revista Estudos Amazônicos do Programa de Pós-Graduação em História Social da Amazônia encontramos: Tomas T. Orum em As mulheres das portas abertas: judias no submundo da Belle Époque amazônica, 1890-1920, que discute acerca das "mulheres que viviam de portas abertas" na condição de prostitutas europeias atraídas pela "prosperidade amazônica" no período da Belle Époque na Amazônia, no jogo entre as cidades de Belém e Manaus; Felipe Tavares Moraes em O campo educacional e o campo político no primeiro governo de Lauro Sodré (1891-1897), que mostra a atuação de Lauro Sodré 
em relação aos ideais republicanos; Ipojucan Dias Campos, no texto Imprensa, divórcio e casamento civil em Belém (1890-1900), o qual observa, através de periódicos do século XIX, as relações sobre o casamento civil e divórcio no cenário bellepoqueano de Belém.

Com base nesse breve retrato de escrita da história sobre o período da Belle Époque, nota-se convergência entre as realidades urbanas de Belém e Manaus. Sabe-se que o período da Belle Époque na Amazônia construiu uma memória da modernização, higienização e ideário de progresso. Aldrin Moura Figueiredo, duvidando dessas mudanças culturais totais, em $A$ Cidade dos Encantados, mostra quão contraditória era essa representação, uma vez que não somente a cidade de Belém seguia embrenhada em antigas tradições, como a arte de curar corpos e espíritos com saberes da medicina tradicional sob a orientação e trabalhos de incorporação de pajés, mas também os próprios agentes da modernização e construção do patrimônio bellepoquiano vez ou outra eram surpreendidos recorrendo às orientações daqueles guias da floresta que habitavam a Petit Francesa da Amazônia.

Com isso, não se pretende negar as reais mudanças provocadas na Belém antes de 1870 a 1920, como o processo de urbanização intenso no centro da cidade. Igualmente, não se duvida de uma vida de riqueza e prosperidade econômica, social, funcional, política e cultural, especialmente para elites da borracha. Pensando o caráter e importância de patrimônios edificados em cidades amazônicas, a escolha desses espaços "monumentalizados", como Belém, traz à tona a escrita de um passado presente em evidências históricas na construção de prédios, igrejas, coretos, praças, assim como produção de documentos/monumentos (LE GOFF, 1990).

O presente estudo é resultado do cruzamento entre documentos escritos acerca da história, cotidiano e patrimônio marajoara com aportes teóricos dos Estudos Culturais e História Cultural. O uso das fontes empíricas orienta-se por uma perspectiva crítica, adotando-se "normas e valores com quais critica textos, produções e condições que promovam opressão e dominação" (KELLNER, 2001, p. 125). Usa-se também o documento enquanto algo negociado entre seu conteúdo e o seu pesquisador. Jean Meyriat dirá que “o 
documento não é um dado, mas o produto de uma vontade, aquela de informar ou se informar, a segunda menos sendo sempre necessário" (ORTEGA; LARA, 2010). De acordo com a Escola dos Annales também se pode encontrar novas concordâncias sobre a ideia de documento: "O historiador não é mais um homem capaz de construir um Império. Nem usa mais o paraíso de uma história global. Ele chega a circular em torno das racionalizações conquistadas. Ele trabalha nas margens" (CERTEAU apud LUCA, 2005, p. 112).

Durante toda a pesquisa foram analisados relatórios do Museu Paraense Emílio Goeldi, relatórios de viajantes em expedição científica pela Amazônia no período imperial e republicano e principalmente matérias do Jornal do Pará, de 1870 a 1878. A análise dos dados levantados não adotou a concepção dual de verdadeiro x falso, mas tentou escavar os sentidos que os documentos produziam ao noticiarem uma temática em determinado tempo e espaço. Se os documentos podem também ser lidos enquanto espaço de ficção, é preciso saber que "ficção não se opõe à verdade: designa as figuras que modelamos, para darmos conta da complexidade e vastidão infinitas do mundo" (MENESES, 2000, p. 31). Portanto, a pesquisa documental enquanto produtora de investigação e síntese das ciências, "propõe-se a produzir novos conhecimentos, criar novas formas de compreender os fenômenos e de conhecer a forma como estes têm sido desenvolvidos" (SÁ-SILVA; ALMEIDA; GUIDANI, 2009, p. 14).

No que tange ao pensamento dos principais intelectuais que ajudaram a apreender aspectos da realidade patrimonial em estudo, dialogouse com Maria Cecília Londres Fonseca (2009). A autora, acompanhando a trajetória de construção do patrimônio histórico e artístico no Brasil, demonstrou em sua pesquisa como a trajetória da política federal de preservação do patrimônio aconteceu no Brasil e como a ideia de patrimônio histórico e artístico nacional está vinculada a ideia de uma configuração de identidade brasileira.

Nesse mesmo sentido, mas analisando a realidade patrimonial da Europa ocidental desde o século XVIII, Françoise Choay (2006) discute o a constituição da ideia de patrimônio ocidental, seus valores, seu culto e também demonstra a tradição de pensar o patrimônio e a memória ocidentais. Outros intelectuais brasileiros se debruçaram sobre o patrimônio nacional. Gil- 
berto Velho (2006) dialoga sobre a dinâmica e os conflitos por quais passam o patrimônio cultural afro-brasileiro, Ricardo Pacheco (2010) mostrará a importância de dispor sobre o patrimônio enquanto dispositivos de educação (não tradicional) da memória. Os estudos do patrimônio convidam ao diálogo com a temática da identidade e da memória e suas formas de esquecimento e silêncio.

Michael Pollak (1989) partindo de uma perspectiva construtivista na análise de memórias subterrâneas ressalta sua importância na compreensão da história de minorias excluídas e marginalizadas pela história oficial. Para o conceito de identidade cultural, Stuart Hall (2006) partindo de uma análise sobre a identidade cultural na modernidade tardia irá avaliar a chamada "crise de identidade" na pós-modernidade. Donizete Rodrigues (2012) também colocará questões da identidade cultural em seu trabalho e, com a perspectiva antropológica, discutirá o que é memória social, patrimônio cultural e identidade e a relação entre os mesmos.

Outros estudiosos da memória e história como Jacques Le Goff (2003), que historiciza sua presença no campo das ciências humanas. Helenice Rodrigues da Silva (2002) apresenta uma análise dos mecanismos das apropriações dos tempos históricos, os processos de construção e de transmissão de uma memória social e a relação entre memória e história por via das comemorações nacionais. O trabalho de Helenice dialoga com o patrimônio como representação de uma memória coletiva da nação em torno de uma legitimidade. (também abordado por Maria Cecília Londres Fonseca). Já Paolo Rossi (2010), semelhante a outros intelectuais da memória, aponta a indissociabilidade entre lembrar e esquecer. Sobre representação, Roger Chartier propõe uma reflexão acerca dos sentidos da apropriação que diferentes grupos sociais fazem das práticas sociais.

\section{Patrimônio e Memória}

Dentro da dinâmica cultural e memorial das noções de patrimônio dentro e fora do Brasil, o patrimônio é hoje, também, fruto de um legado de perspectiva nacionalista moderna. A noção moderna de patrimônio surge no século XVIII caracterizada, de acordo com Fonseca (2009, p. 58), "pelo conjunto de bens de valor cultural que passaram a ser propriedade da nação, ou 
seja, do conjunto de todos os cidadãos." Ela é fruto do atributo do valor de nacionalidade dado pela intervenção do Estado e "intelectuais de cultura". Nesse sentido, aquilo que se chama de patrimônio nacional pode ser conferido enquanto uma construção simbólica e seletiva do Estado na escolha de bens que representem a história da nação. De acordo com Fonseca (2009, p. 58) existiram alguns fatores que fizeram o patrimônio se erguer enquanto propriedade da nação no século XVIII. São eles: atos de vandalismo, ideias iluministas e derrubada do poder do clero e da Igreja que não poderiam mais administrar seus bens. Assim a

noção de patrimônio é, portanto, datada, produzida, assim como a ideia de nação, no final do século XVIII, durante a revolução francesa, e foi procedida, na civilização ocidental, pela autonomização das noções de arte e de história. O histórico e o artístico assumem, nesse caso, uma dimensão instrumental, e passam a ser utilizados na construção de uma representação de nação (FONSECA, 2009, p. 37).

Para que as políticas de preservação se façam cumprir, serão impostos valores ao patrimônio e esses ditarão quais e porque deverão ser preservados. O atributo do valor nacional será o propulsor e em seguida surgem valores como o cognitivo, econômico, artístico, histórico, de novidade, de uso, entre outros. Mas, os valores principais que irão motivar as políticas de preservação são os valores históricos e artísticos.

Fonseca (2009, p. 65) aponta que as ideias concebidas para história e para a arte no renascimento eram somáticas, mas a noção de história, diferentemente da arte, não exigia a existência de um cânone histórico, ela seguia a afirmação de um valor específico de cada período. Poder-se-ia dizer que o valor histórico possui um ponto de vista que motivaria as coisas a terem seus valores a seus respectivos tempos e não referenciados apenas em fator de tempos antigos canonizados.

Em análise das concepções fundamentais da noção de patrimônio no Brasil, mais precisamente a partir da década de 20, grande parte das cidades do período colonial, seus prédios, praças e tudo que venha a ser declarado vestígio do passado perante aos valores históricos e artísticos, irão ser objeto das políticas preservacionistas do Estado. É com a criação do Serviço do 
Patrimônio Histórico e Artístico Nacional (SPHAN) em 1936, juntamente com os intelectuais modernistas, que irão se instituir as imagens referentes à constituição do patrimônio. Dentro do programa de trabalho do SPHAN existia um padrão quando se tratava da questão do tombamento, pois a prioridade dava-se seguindo a ideia de que "a civilização estava nos países desenvolvidos da Europa e da América do Norte, e que a única maneira de o Brasil civilizar-se era imitar esses modelos" (FONSECA, 2009, 107).

É somente no século XX, com a ampliação da noção de patrimônio, que começarão a ser introduzidos novos personagens patrimoniais esquecidos pela história factual. Também, é em 1945 que se começa a pensar, nas ex-colônias, o patrimônio como apropriação da noção europeia (FONSECA, 2005), portanto, esse trabalho também pode ser considerado um exercício crítico sobre patrimônios esquecidos no vigente século XXI.

Neste artigo, insiste-se na ideia de que o patrimônio histórico, além ser um bem destinado à coletividade, é um evento que monta e remonta memórias e expressões de identidades. De acordo com Pollak (1992, p. 202), o patrimônio é um lugar de memória, e, no caso do Estado, este irá enquadrá-lo a uma memória para que a nação possa "manter a coesão interna e defender as fronteiras daquilo que um grupo tem em comum, em que se inclui o território, eis as duas funções essenciais da memória comum. Isso significa fornecer um quadro de referência e de pontos de referência” (POLLAK, 1989, p. 09).

Dentro da ideia de memória enquadrada e pelo imaginário que se cria, Stuart Hall (2003) observa que a relação identidade e nação, enquanto representação partilhada, sempre é mantida com base em representações de acontecimentos gloriosos, primordial para uma fundação histórica e um povo unificado, pois "não importa quão diferentes seus membros possam ser em termos de classe, gênero ou raça, uma cultura nacional busca unificá-los numa identidade cultural, para representá-los todos como pertencendo à mesma e grande família nacional" (HALL, 1992, p. 50).

É diante desse caráter de unificação da nação que Hall sustenta a comunidade nacional como algo imaginado, pois a maioria das na- 
ções se constitui de misturas culturais, raciais, de gêneros e classes. Portanto, o patrimônio nacional pode também ser lido sob uma perspectiva imaginada, pois querendo representar uma identidade nacional, põe-se a representar uma nação que não existe enquanto uma única identidade cultural, e sim enquanto várias identificações culturais. Logo, a escolha de patrimônios que representem uma memória nacional universal irá coexistir com conflitos de gênero, de raça, econômicos, sociais e culturais, pois as memórias, além de se constituírem enquanto lembrança, também são reais em fator de esquecimentos. Logo, ao selecionar patrimônios em fator de outros, coloca-se em cheque o caráter da memória e a sua função de lembrar e esquecer: ao selecionar um, esquece-se do outro. Lembrar e esquecer são ações biológicas, sociais e culturais que nos dão a capacidade de saber quem somos e pontuar nossas atitudes no dia-a-dia.

A partir da prática de lembrar o esquecido da história do patrimônio amazônico que se apresenta o fenômeno do patrimônio marajoara bellepoqueano, pois, "se não se deve esquecer é também e, sobretudo, em razão da necessidade de se honrar as vítimas da violência histórica” (SILVA, 2002, p. 437).

Em busca dos sentidos da memória, "ideia imperativa de um 'dever de memória' e de uma "divida" em relação às vítimas da história, [...]" (RICOEUR apud SILVA, 2002, p. 436) é que será analisado o Marajó na conjuntura de grande produtor gomífero, esquecido em sua relevância patrimonial. Em detrimento da nova maneira de escrever a história, coloca-se a importância ética no trato da produção da escrita, pois o "apagar” não tem a ver só com a possibilidade de rever a transitoriedade [...]. Apagar também tem a ver com esconder, ocultar, despistar, confundir os vestígios, afastar da verdade, destruir a verdade (ROSSI, p. 32).

Assim, parte-se da necessidade de estudar o patrimônio pela ótica do Estado, mas também, perceber no discurso oficial, as apropriações e usos do patrimônio que não necessariamente seguem a lógica da elite ou dos representantes do poder. O importante é perceber que mesmo através desses discursos oficiais podemos entender as ressonâncias e apropriações que tomam o patrimônio em vários setores da sociedade. Vale-se do conceito de apropriação 
enquanto um critério que move o fenômeno da (re)presentação e que "visa a uma história social dos usos e das interpretações, referidas a suas determinações fundamentais e inscritas nas práticas específicas que as produzem" (CHARTIER, 1991, p, 180).

Dentro de uma descontinuidade histórica do patrimônio, pretende-se mostrar como outras comunidades, Marajó dos Campos e Marajó das Florestas na Belle Époque, concebem uma leitura ao patrimônio, pois, é muito importante pensar o patrimônio sob uma ótica que vá além de uma ordem de pensamento universal, mas entendê-la na circulação de sentidos, significados atribuídos e as suas apreensões sociais nos discursos. Para isso, torna-se importante pensarmos que "a leitura não é somente uma operação abstrata de intelecção: é por em jogo o corpo, é inscrição num espaço, relação consigo e com o outro" (CHARTIER, 1991, p. 181).

É importante salientar a sintonização e (des)sintonização das ideias de patrimônio, memória e identidade. Quando um discurso oficial nomeia certo monumento como patrimônio nacional e todos o "reconhecem" enquanto tal, existe uma certa sintonia, então, o patrimônio revela uma memória passada e fomenta uma identidade presente. Neste caso, o patrimônio pode ser entendido enquanto um "conjunto de símbolos sacralizados, no sentido religioso e ideológico, que um grupo, normalmente a elite, política, científica, econômica e religiosa, decide preservar como património coletivo" (RODRIGUES, 2012, p. 04).

Mas quando esse mesmo discurso permeia uma sociedade que não reconhece o valor do patrimônio tal como foi plantado, as imagens sobre o patrimônio tornam-se (des)sintonizadas da memória e consequentemente da identidade desenhada, fazendo surgir o lado conflituoso das relações com o patrimônio. Entende-se este conflito, a partir de Stuart Hall, quando não há uma correspondência entre o momento da produção e o da recepção das mensagens, o conflito se faz presente.

Enquanto produto cultural, o patrimônio "é uma produção. Tem sua matéria-prima, seus recursos, seu "trabalho produtivo". Depende de um conhecimento da tradição enquanto 'o mesmo em mutação' e de um 
conjunto efetivo de genealogias" (HALL, 2003, p. 44). As posições de representações dependem de como o indivíduo irá motivar seu olhar diante da dinâmica memorial e identitária que tomam os patrimônios, pois, "os indivíduos são ao mesmo tempo herdeiros de disposição e capazes de inventar, de produzir novas formas de ação" (MAIGRET, 2010, p. 229). O importante é fazer entender que, independentemente de toda ideologia aplicada ao patrimônio, as formas em que se dão as apropriações são diversas.

\section{O Patrimônio Bellepoqueano dos Marajós}

O patrimônio marajoara no período da Belle Époque irá ser analisado diante da cultura marajoara descrita pelos documentos. Portanto, foi preciso entender como era a vida na região nesse período, quais transformações ocorreram na dinâmica social dos municípios e seu patrimônio e como a região de campos e florestas e seus municípios vivenciaram os chamados tempos da economia da borracha na Amazônia. Toma-se como análise o conceito de cultura enquanto "O próprio material de nossas vidas diárias, as pedras fundadoras de nossas compreensões mais corriqueiras” (PAUL WILLIS, 1977, p. 185 apud NELSON, 2005, p. 14).

Tenta-se imbricar a noção de cultura, um dos caminhos a serem tratados na pesquisa, aos patrimônios e suas instâncias no imaginário. É preciso saber delimitar que, quando se fala de imaginário, está-se propondo modos diferentes de se operar com a cultura e reconstituir a realidade. Assim, quando se discute patrimônio bellepoqueano marajoara, procura-se evidenciar, dentro do discurso oficial e popular, quando é possível rastrear, uma configuração de patrimônio referente a um imaginário próprio do tempo e espaço marajoara. Por imaginário entende-se um "conjunto de representações que exorbitam do limite colocado pelas constatações da experiência e pelos encadeamentos dedutivos que estas autoriza" (PATLAGEAN, 1978, p. 391-392).

Antes de 1870, Bates, em uma das suas viagens ao interior da Amazônia, descreve Gurupá enquanto "uma área pedregosa isolada, pois o resto da região é baixo e sujeito a inundações na época das chuvas" (BATES, 1973, p. 36). Os naturalistas e viajantes que percorreram rios e localidades amazônicas no século XIX, a exemplo de Bates, procuravam registrar diferentes 
aspectos da vida na região como as questões sociais, ambientais e econômicas. Vê-se na escrita de Emilio A. Goeldi em Maravilhas da Natureza na I lha do Marajó o relato sobre a grande ocupação econômica da borracha no Marajó das Florestas: "na metade sudoeste, em que predomina a floresta virgem, tipicamente amazônica, expande-se, sob o signo do Aquário, a colheita da borracha" (GOELDI, 1899, p. 371, grifou nosso). É sempre importante colocar o quanto a borracha foi para esses municípios um dos maiores convergentes econômicos da época, como já foi dito anteriormente, Breves exportou cerca de 1.547.374 quilos de do produto em 1900 (WEINSTEIN, 1993, p. 323). A borracha era um dos produtos substanciais da economia marajoara, juntamente com a atividade pecuária e agrícola.

Produtos exportados no Marajó dos campos e das flores-

tas em 1875.

\begin{tabular}{|c|c|}
\hline Região & Produtos exportados \\
\hline Melgaço & Borracha, castanhas, couros de veado e madeira \\
\hline Portel & Borracha e farinha \\
\hline Gurupá & Borracha, cacau, salsa e castanha \\
\hline Chaves & Borracha e gado \\
\hline Breves & Borracha, tijolos, louças, telhas e andiroba \\
\hline Curralinho & Borracha e cacau \\
\hline Cachoeira & Borracha e gado \\
\hline Monsarás & Gado e farinha \\
\hline Soure & Gado \\
\hline
\end{tabular}

Fonte: CENTUR, O Jornal do Pará, N. 78, p. 01

Frente à notável quantidade de produtos exportados da Amazônia, vê-se que o Marajó foi um lugar de grande importância no quadro econômico da Belle Époque, pois a maioria dos seus municípios funcionavam enquanto produtores e exportadores da borracha, especialmente no Marajó das Florestas. Assim, em termos econômicos, os Marajós eram grandes produtores de gado pelos campos e um grande produtor de borracha pelas florestas:

A mais rica e importante indústria da ilha de Marajó é a criação do gado vaccum, para o que há campos vastissimos que ocupam um pouco mais da metade da superfície da ilha. $\mathrm{Na}$ contra-costa há uma boa olaria em que se fabrica telhas, tijolos e louças vermelhas. No município de Muaná, cultiva-se ainda o cacáo e, como no baixo Arary, há boas plantações de canna e 
um bom número de engenhos em que se fabrica aguardente e uma quantidade de assucar. Com estas excepções, o gado nos campos e a borracha nas mattas são as únicas producções da ilha (O JORNAL DO PARÁ, 1876, n. ${ }^{\circ}$ 26, p. 01).

Pensando o Arquipélago de Marajó enquanto um grande produtor e exportador de borracha, como toda essa economia irá responder às demandas sociais dos espaços urbanos marajoaras? Também, como é possível entender a dinâmica do patrimônio perante a um lugar onde, no inverno, muitos dos seus municípios são alagados, formando vastas ilhas? É importante ter em mente as condições ambientais com a qual os marajoaras são obrigados a enfrentar e a sua relação frente às condições culturais vivenciadas na região. Sabe-se que os Marajós são cercados por rios que no inverno tomam os campos, alagando-os. Dentro dessa característica ambiental, o interessante é pensar que o mesmo rio que gera a borracha, alaga as construções dos municípios. Pode-se entender essa dinâmica em Chaves:

os ventos são com effeitos muito rijos, agitando muito as aguas do rio e tornando perigoso o movimento de cargas e passageiros. Póde-se dizer que a villa tem mais de uma vez mudado de lugar, recuando para o campo; o antigo quartel ocupava outr'ora mais ou menos o lugar em que hoje fundea o vapor da companhia do Amazonas, e aquelle em que existiu a antiga igreja matriz é hoje o limite inferior da praia na maior baixa-mar, cerca de 240 metros da villa actual; e muitas casas modernas estão sendo olvidas e desmoronadas a medida q o terreno alto em que foram construídas se vae desfazendo em cada anno pelo efeito do embate das ondas (O JORNAL DO PARÁ, 1876, nº 26, p. 01).

Diante dessa dinâmica ambiental dos rios, o modo como as populações marajoaras vão operar culturalmente poderá ser analisado a partir, também, da relação com as dinâmicas ambientais. A dinâmica do patrimônio no Marajó está pautada, também, na relação de homens e mulheres com o regime das águas (PACHECO, 2009). Vendo a cultura, enquanto "processo social fundamental que modela 'modos de vida' específicos e distintos" (WILLIAMS, 1979, p. 23), pode-se perceber que as condições patrimoniais dentro do Marajó vão 
estar relacionadas a uma dinâmica cultural diferenciada. Um exemplo emerge da observação registrada em uma das matérias d'O Jornal do Pará a respeito da relação do ensino escolar e do trabalho da borracha:

O estado do ensino no interior da provincia nada tem de lisongeiro; a matricula dos alumnos é, quase sempre, uma fição official e a relação da frequencia as vezes não o é menos. "O mal tem sua origem principal nos habitos, costumes e frequentemente nas necessidades ou falta de recursos da maioria dos habitantes, mormente dos que nunca tiveram instrucção alguma. "Lá para fins de Janeiro os paes começam a regressar à povoação trazendo consigo os filhos que muitos fazem logo matricular na escóla. O professor ou professora faz a inscripção no livro de matricula, abrem-se as aulas e os discipulos as frequentam 3,4 ou 5 mezes. "No fim d'este periodo, os paes que, na forma habitual, tem de prepararse para a safra da borracha, vem pedir dispensa dos filhos e filhas, estas para ajudarem a fazer a farinha, e aquelles para lhes ajudarem a ajuntar caroços de urucury, necessarios para a defumação da borracha (O JORNAL DO PARÁ, 1876, n 31, p. 01-02).

Atravessada por uma concepção de progresso, instrução letrada pautada no modelo de educação francesa, o cotidiano escolar da região no século XIX deixa ver precários índices de frequência escolar pelas dificuldades que os trabalhadores rurais tinham de ficar durante um ano em uma única área da região. Os modos de vida nos Marajós fundem vida social, ambiental e econômica.

De acordo com O Jornal do Pará, outra indústria que ascende no Marajó, concomitante à criação do gado, é o roubo dos mesmos. Os fazendeiros são os que mais furtam o gado no Marajó, seja pelo costume, para criar, comer, e até para variar de alimento. Assim, o roubo do gado no Marajó deixa de ser apenas um fator econômico, pois, "é um habito que tem passado inalteravelmente de tataravós a tataranetos, de geração a geração, e que tido a sancção de mais de um seculo. Em outros termos: o furto de gado em Marajó é um costume e um costume tradicional" (O JORNAL DO PARÁ, 1876, N. ${ }^{\circ}$ 38, p. 01, 17, Quinta-Feira). 
Os tempos da Belle Époque na região, de acordo com o jornal, mostram-se vivos perante as práticas dos seus moradores. Entende-se que exista uma certa atenção a esses roubos como sendo de domínio cultural. A dinâmica do roubo é marcada pela memória dos marajoaras. Infere-se que, além do seu valor econômico, existe uma carga simbólica e mesmo afetiva no ato do roubo do gado.

Sobre as condições de vida no Marajó, encontra-se como estava a situação urbana e as edificações dos municípios mais citados pelo $O$ Jornal do Pará: Melgaço, Portel, Gurupá, Chaves, Breves, Curralinho, Muaná, Cachoeira, Monsarás e Soure.

O município de Melgaço, registrado pelo O Jornal do Pará, possuía um igreja matriz, uma cadeia, uma escola primaria para homens e com o estado sanitário em níveis péssimos de qualidade. O município de Portel possuía uma igreja matriz, a casa das sessões municipais e cadeia, três escolas, duas públicas e uma particular e o estado sanitário está em nível deplorável, mas já esteve ótimo em 1868. Em Gurupá

o governo colonial fortificou Mario-Cay um forte em ruinas, possui um porto por onde fazem os transportes com os vapores da Companhia do Amazonas, os edifícios públicos são a Igreja matriz, a casa da câmara, cinco escolas públicas, o estado sanitário satisfatório e muros derrocados da antiga fortaleza. Em Chaves existem duas igrejas matrizes, uma nova em construção e a antiga que já está em ruínas, uma cadeia e uma casa da câmara, três escolas públicas e o estado sanitário não sofreu alteração, quase sempre muito satisfatório. Em Breves, mostra-se presente uma igreja matriz, a casa da câmara e também fabrica-se uns vasos pintados de cores vivas, que são muito estimados dos curiosos por considera-los como parte como producto da industria indigena (O JORNAL DO PARÁ, 1875, n. 75 , p. 1).

Além desses bens patrimoniais urbanos, Breves possuía um porto, duas escolas primárias, estado sanitário com níveis melhorados e precisando de uma cadeia que neste período ocupava um casebre em ruinas. Curralinho possuía uma excelente igreja matriz, duas escolas de ensino primário, um porto e com o estado sanitário quase satisfatório. No município de Muaná, existia 
uma igreja matriz, uma casa municipal, um quartel que servia de cadeia e 82 casas habitadas, cinco casas de comércio, duas padarias, três alfaiates e dois sapateiros e duas escolas de ensino primário. Porém, a localidade

pede a construcção d'uma estacada para impedir o desmoronamento das casas situadas a beira do rio, o concerto do cemiterio e reparos urgentes do quartel na parte que serve de cadêa, em ruinas, e outras medidas que a camara julga necessarias o para cuja execução não tem ella rendas suficientes (idem).

Monsarás possuía uma igreja matriz, três escolas de ensino primário e sem nenhum desgaste no sistema sanitário de saúde. Por último, Soure possuía seis escolas e uma escola noturna, a casa da fazenda nacional São Lourenço, uma igreja matriz que tem sua sacristia servindo de cadeia e quartel da guarda.

Entre as principais representações do patrimônio bellepoqueano marajoara não se encontra o patrimônio legitimado pelo valor de nacionalidade ou outros valores constituintes, mas pode-se entender que hoje esses marcadores constituem os indícios de patrimônios situados no início da Belle Époque na Amazônia marajoara. Esse trabalho também se constitui para evidenciar que o patrimônio marajoara não prescinde apenas das famosas urnas e cerâmicas marajoaras, mas que outros patrimônios podem ressonar vozes diante do estado mais democrático (a partir dos anos de 1870) que se encontram as questões patrimoniais hoje no Brasil e no mundo.

\section{Considerações Finais}

O planejamento para a escrita deste ensaio procurou situar a importância de se estudar o patrimônio marajoara no período da Belle Époque, principalmente pelo fato da alta participação dos municípios marajoaras na época do boom do ciclo da borracha na Amazônia. Com base em teóricos do patrimônio e da memória, procurou-se entender, mesmo nesses primeiros anos do período da exploração da borracha, como ficou estruturada a vida dos marajoaras desse período e quais as ressonâncias que se conseguiu captar em relação à memória e ao patrimônio no Marajó dos Campos e Marajó das Florestas. 
Somado a isto, foi na empiria do O jornal do Pará e com os registros dos viajantes e cronistas que, de acordo com estudiosos no tratamento de documento escrito, explorou-se uma metodologia de análise crítica diante de representações e práticas oficiais de patrimônio marajoara em tempos de Belle Époque.

Um aspecto importante no interpretar das letras do $O$ jornal do Pará e dos relatos dos viajantes e naturalistas foi a grande evidência do olhar ante a dinâmica dos rios, da agricultura e da pecuária. Tudo o que foi falado, na maioria das vezes, possui análises em relação ao ambiente, ora o rio, outrora o gado. Assim, optou-se por situar o patrimônio diante das dinâmicas ambientais, econômicas, geográficas dos Marajós. Diante desse aspecto, é importante entender que o patrimônio na região marajoara existe em relevância a um local onde as dinâmicas naturais permeiam o cotidiano de todos, ou melhor, onde as dinâmicas naturais e culturais não funcionam enquanto operações separadas. Logo, o patrimônio marajoara em tempos de Belle Époque se propõe a um trabalho onde procura mostrar também que o cultural e o natural vivem em constantes diálogos.

\title{
UNDER THE SIGN OF AQUARIUS: THE MARAJOARA HERITAGE IN THE BELLE EPOQUE
}

\begin{abstract}
The purpose of this article is analysing the representation of the cultural heritage of Marajoara Amazon in the period of the Rubber Boom (1870-1912), especially with regards to the constructions and the displacements in urban spaces of the municipalities of Marajó dos Campos and Marajó das Florestas. The main problem was trying to understand what public inheritance in Marajoara cities originated in the famous Rubber Boom in the Amazon. To understand this issue, our research embarked in a dialogue with two types of sources: a) scholars specialised in the study of the Rubber Boom, of the heritage, of memory and identity; b) reports by chroniclers, travellers and journalists who collected information on Majoara urban life, with an attention to buildings, habits, coexistences and tensions, between the last decades of 19th century and the first two decades of the 20th century.
\end{abstract}

KEYWORDS: Heritage. Belle Epoque. Marajoara Amazon. 
Josiane Martins Melo, Agenor Sarraf Pacheco

\section{Referências}

BATES, H. W. A Grande Aventura de Bates. Extraído do Livro O naturalista no rio Amazonas. Tradução de Candido de Melo Leitão, revista e condensada por Mário Garcia de Paiva. Coleção documentos 8; Instituto Nacional do Livro, Brasília, 1973.

CAMPOS, I. D. Imprensa, divórcio e casamento civil em Belém (1890-1900). Revista Estudos Amazônicos. Volume V, n. 1, 2010, pp. 173-191.

CHARTIER, R. O mundo como Representação. Estudos Avançados, 05, n. 11. São Paulo, Jan/Abr, 1991.

CHOAY, F. A Alegoria do Patrimônio. Trad. Luciano Vieira Machado. $4^{a}$ ed. - São Paulo: Estação Liberdade: UNESP, 2006.

DIAS, E. M. A ilusão do Fausto- Manaus 1890-1920. Editora Valer, Manaus, 1999, pp. 11-30.

FIGUEIREDO, A. M. A Cidade dos Encantados: pajelanças, feitiçarias e religiões afro -brasileiras na Amazônia 1870-1950. Belém, EDUFPA, 2008, pp. 20-30.

FONSECA, M. C. L. O Patrimônio em Processo: trajetória da política federal de preservação no Brasil. 3. Ed. Rev. Ampl. Rio de Janeiro: Editora UFRJ, 2009.

GOELDI, E. Maravilhas da Natureza na Ilha de Marajó (rio amazonas) - conferência pelo Prof. Dr. Emilio a. Goeldi, na sociedade de geografia de berne (Suíça) em 29 de junho de 1899, pp. 370-399.

HALL, S. A identidade cultural na pós-modernidade. 7. Ed. Rio de Janeiro: DP\&A Editora, Rio de Janeiro, 11. ed. 2006.

HALL, S. Pensando a diáspora: reflexões sobre a terra no exterior. In: Da Diáspora: identidades e mediações culturais. Tradução Adelaine La Guardiã Resende... [et. al]. Belo Horizonte: Editora UFMG; Brasília: Representação da UNESCO no Brasil, 2003, pp. 25-50.

KELLNER, D. Por um estudo cultural, multicultural e multiperspectívico. In: A Cultura da Mídia: estudos culturais: identidade e política entre o moderno e o pós-moderno. Tradução Ivone Castilho Benedetti. Bauru, SP: EDUSC, 2001, pp. 123-160.

LE GOFF, J. Documento/Monumento. In: História e memória. 5 Ed. Trad. Bernardo Leitão. Campinas, SP. Editora da UNICAMP, 2003, pp. 525-541

LACERDA, F. G. Migrantes Cearenses no Pará: faces da sobrevivência (1889-1916). Belém: Ed. Açaí, 2010, pp. 11-25.

LUCA, T. R. Fontes impressas: História dos, nos e por meio dos periódicos. In: Fontes Históricas. Org. Carla Bassanegi Pinsky. São Paulo: Contexto. 2005, pp.111-153.

MAIGRET, E. Os Estudos Culturais. In: Sociologia da comunicação e das mídias. Tradu- 
ção de Marcos Bagno. São Paulo: Editora Senac São Paulo, 2010, pp. 223-249.

MENESES, U. T. B. O museu e o problema do conhecimento. In: IV Seminário sobre Museus-casas: Pesquisa e Documentação, 2002, Rio de Janeiro. Anais do IV Seminário sobre Museus-casas: Pesquisa e Documentação. Rio de Janeiro: Fundação Casa de Rui Barbosa, 2000, pp. 17-48.

MORAES, F. T. O campo educacional e o campo político no primeiro governo de Lauro Sodré (1891-1897). Revista Estudos Amazônicos. Volume VII, n 1, 2012, pp. 117-149.

NELSON, C. Estudos Culturais: uma introdução. In: SILVA, Tomaz Tadeu da (org.). Alienígenas na sala de aula: uma introdução aos estudos culturais em educação. $6^{a}$. ed. Tradução de Tomaz Tadeu da Silva. Petrópolis, RJ: Vozes, 2005, pp. 07-38.

ORTEGA, C. O; LARA, M. L. G. A noção de documento: de Otlet aos dias de hoje. DataGramaZero, Revista da Ciência da Informação, v. 11, n. 2, abr. 2010.

PACHECO, A. S. Cartografia de Memórias na Amazônia. In: PACHECO, Agenor Sarraf e SILVA, Jerônimo da Silva e (Org.). Pesquisas em Estudos Culturais na Amazônia. Belém, 2013 (No prelo).

PACHECO, A. S. En el corazón de la Amazonía: identidades, saberes e religiosidades no regime das águas marajoaras. Tese (Doutorado em História Social), PUC-SP, 2009.

PATLAGEAN, E. A história do Imaginário. In A nova História. Coimbra, Almedina, 1978, pp. 391-427.

POLLAK, M. Memória e Identidade Social. In: Estudos Históricos. Rio de Janeiro, vol. 5, n. 10, 1992, pp. 200-212

POLLAK, M. Memória, esquecimento, silêncio. In: Estudos Históricos. Rio de Janeiro, vol. 2, n. 3, 1989, pp. 3-15.

RODRIGUES, D. Patrimônio cultural, Memória social e Identidade: uma abordagem antropológica. UBImuseum- Revista Online do Museu de Lanifícios da Universidade da Beira interior, n. 01, 2012, pp. 1-08.

ROSSI, P. “Lembrar e esquecer". In: O passado, a memória, o esquecimento. São Paulo: Ed. UNESP, 2010, pp. 15-38.

SARGES, M. N. Memórias do "Velho Intendente" Antônio Lemos (1969-1973). Belém: Paka-Tatu, 2002, pp. 15- 30.

SARGES, M. N. O Pará na economia da Borracha: transformações econômicas e sociais. IN Belém: riquezas produzindo a Belle Époque (1870-1912). Ed. 3, Paka-Tatu, Belém, 2010.

SÁ-SILVA, A.; GUIDANI, J.; Cristovão, J. Pesquisa documental: pistas teóricas e meto- 
Josiane Martins Melo, Agenor Sarraf Pacheco

dológicas. Revista Brasileira de História \& Ciências Sociais, ano I, - número I, - Julho de 2009, pp. 1-14.

SILVA, H. R. Rememoração/comemoração: as utilizações sociais da memória. Revista Brasileira de História, São Paulo, v. 22, nº 44, 2002, pp. 425-438.

T. ORUM, T. As mulheres das portas abertas: judias no submundo da Belle Époque amazônica. Revista Estudos Amazônicos. Volume VII. N. 1, 2012, pp. 01-23

WEINSTEIN, B. A borracha na Amazônia: expansão e decadência 1850-1920. São Paulo: HUCITEC: Editora da universidade de São Paulo, 1993.

WILLIAMS, R. Marxismo e Literatura. Rio de Janeiro: Zahar, 1979.

HISSA, E. C. V. Entrenotas: compreensões de pesquisa. Belo Horizonte: Editora UFMG, 2013.

Data de recebimento: 16/07/2014

Data de aceite: 17/08/2014 